\title{
Quality of management for acute respiratory tract infections and diarrhoeal diseases in rural Yemen
}

H.H. Al-Hamzi, ${ }^{1}$ L.M. Al-Zubairi, ${ }^{2}$ Y.A. Raja'a, ${ }^{2}$ A. Y. Al-Dabagh ${ }^{3}$ and N.M. F. Al-Bayatti ${ }^{3}$

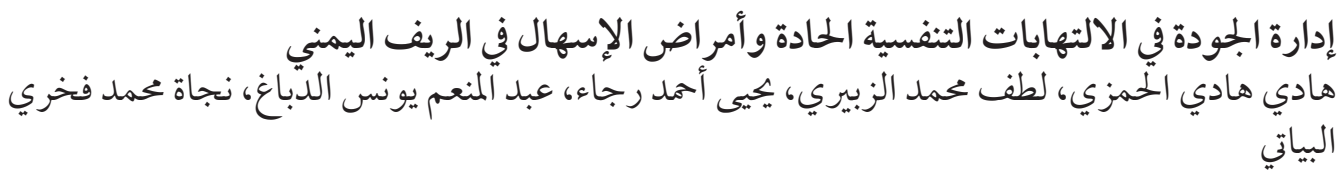

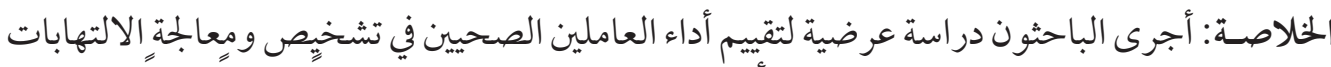

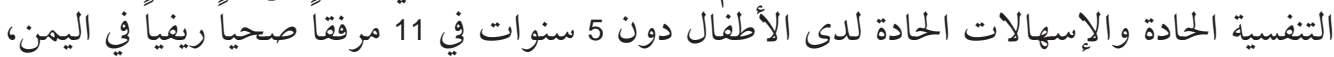

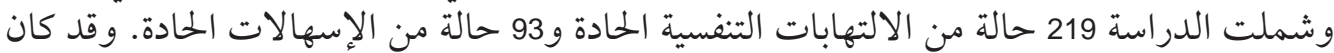

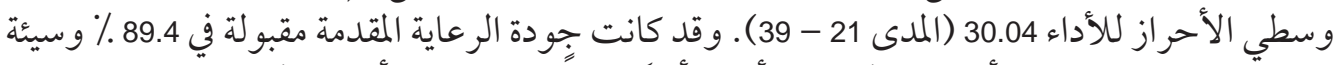

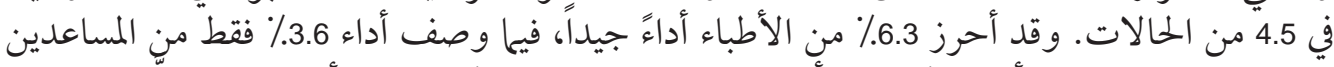

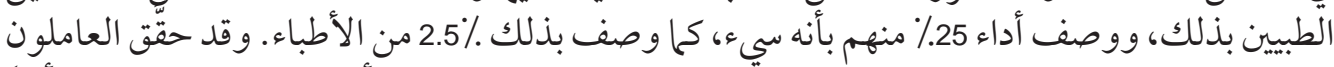

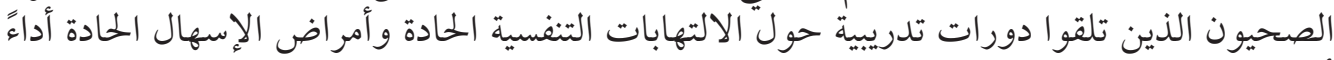

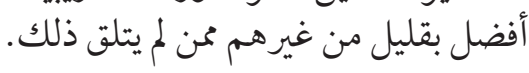

ABSTRACT To evaluate the performance of health workers with respect to diagnosis and treatment of acute respiratory infection (ARI) and acute diarrhoea $(A D)$ in children $<5$ years in 11 rural heath facilities in Yemen, we carried out a cross-sectional study on 219 cases of ARI and 93 cases of AD. Mean score for performance was 30.04 (range 21-39). The quality of care provided was fair in $89.4 \%$ and poor in $4.5 \%$ of cases. A "well done" performance of $6.3 \%$ was achieved by medical doctors but only $3.6 \%$ of medical assistants and $25 \%$ of medical assistants scored "poor" for performance, but only $2.5 \%$ of medical doctors. Health workers who had received training courses in ARI and AD performed slightly better than those who had not.

Qualité de la prise en charge des infections aiguës des voies respiratoires et des maladies diarrhéiques dans le Yémen rural

RÉSUMÉ Afin d'évaluer la performance des agents de santé sur le plan du diagnostic et du traitement des infections respiratoires aiguës (IRA) et de la diarrhée aiguë chez les enfants de moins de 5 ans dans 11 dispensaires ruraux au Yémen, nous avons réalisé une étude transversale de 219 cas d'IRA et 93 cas de diarrhée aiguë. Le score moyen de la performance était de 30,04 (avec des extrêmes allant de 21 à 39). La qualité des soins dispensés était assez bonne dans $89,4 \%$ des cas et mauvaise dans $4,5 \%$. Le niveau de performance « bon » a été atteint par 6,3\% des médecins, mais seulement par 3,6 \% des assistants médicaux ; $25 \%$ de ces derniers ont obtenu un niveau de performance " mauvais ", contre seulement 2,5\% des médecins. Les agents de santé qui avaient reçu une formation sur les IRA et la diarrhée aiguë ont obtenu des résultats légèrement supérieurs à ceux qui n'en avaient pas reçu.

${ }^{1}$ Ministry of Public Health and Population, Sana'a, Yemen.

${ }^{2}$ Department of Community Medicine, Faculty of Medicine and Health Sciences, Sana'a University, Sana'a,

Yemen (Correspondence to Y.A. Raja'a: yahiarajaa@yahoo.com).

${ }^{3}$ College of Medicine, Al-Mustansiriyah University, Baghdad, Iraq.

Received 22/01/07; accepted: 14/05/07

المجلة الصحية لشرق المتوسط، منظمة الصحة العالمية، المجلد الخامس عشر، العدد 0، 9 +. 


\section{Introduction}

The World Health Organization (WHO) estimated in 1995 that 15000 deaths per year could be avoided by the control of the most prevalent childhood illnesses using easy to apply low-cost technologies. Most of the deaths avoided would be related to diarrhoeal infections, acute respiratory infections (ARIs) and malnutrition [1]. Therefore, WHO initiated the Integrated Management of Childhood Infections (IMCI) programme to address this situation. The IMCI package, which targets children aged $<5$ years, includes mainly the management of ARIs, diarrhoeal diseases, malaria and malnutrition [2]. Even so, a number of studies have indicated deficiencies in the care of sick children in many countries [3-6].

Diarrhoeal diseases, including acute diarrhoea (AD), and ARI are leading causes of morbidity and mortality in children $<5$ years in Yemen. The infant mortality rate was 75 per 1000 live births and the mortality rate among children $<5$ years of age was 102 per 1000 live births [7]. Thus, the Government of Yemen adopted ARI and control of diarrhoeal diseases (CDD) programmes in the country in 1995 and 1997 respectively in order to save children's lives.

Since the implementation of these programmes, no systematic study has been carried out to assess their impact on the practices of health workers involved in diarrhoea and ARI case management. Furthermore, the training for management of ARI-AD was conducted on-the-job for health personnel, who had graduated from different schools, in order to unify the practice of ARI-AD management. In addition, quality of service started to be a major concern for both officials and the public. Therefore, an assessment of this new approach to management, which allows paramedics to handle such cases, was needed.
The objective of this study was to evaluate the performance of health workers with regard to the diagnosis and treatment of ARI and diarrhoeal diseases.

\section{Methods}

The data collection for this cross-sectional study was carried out in 6 governorates out of the 20 in Yemen: Sana'a, Amran, Hajjah, Al-Mahweet, Ibb and Mareb. These governorates were selected because the Health Sector Reform project is active there and it includes capacity-building in its activities. We randomly selected 2 rural districts from each governorate except Mareb, where only 1 district was selected due to logistic barriers. One health centre per district was chosen randomly and from each health centre the first 30 targeted cases (complaining of diarrhoea or respiratory tract infection) were enrolled in the study (we considered 30 the lowest reasonable number of responses that we could work with statistically and still be able to make useful inferences from).

We spent 6-8 days at each facility, depending on the attendance rate (average of 3-4 patient visits per day), during the period 25 October 2001 to 15 January 2002. During this time the weather is cold in Sana'a and Amran, so the incidence of ARI was expected to be high. In the other targeted areas the weather was temperate. The topography of the studied areas is generally mountainous, with the exception of Mareb, which makes accessibility to health facilities difficult. Therefore, attendance rate was low, as expected.

A pilot study was carried out in 3 other districts to verify the questionnaire, to adapt to the situation of observation and re-examination of the observed patient and to explore barriers so as to avoid them in the main data collection. 
We directly observed the diagnostic performance of health workers for each child with ARI or diarrhoea and scored their performance according to the basic outline of the WHO algorithm for integrated management of the sick child [2]. The score was based on the reception of the patient, clinical history taking, physical examination, reaching an accurate diagnosis, recording the diagnosis in the register, number of drugs prescribed, decision on antimicrobial therapy, taking into consideration justification and choice, decision on symptomatic drugs for fever and cough according to WHO recommendations, entering of the prescribed drugs into the register, and counselling for the care-giver about alarming signs and home care.

\section{Acute respiratory infection}

For reception and history taking according to WHO guidelines for ARI cases, there were 8 points to cover: presence of cough, duration of cough, ability to drink (for child aged 2 months to 5 years), stopping feeding well (for child $<2$ months of age), presence of fever, presence of convulsions, whether the child had a period of not breathing or turning blue, and history of recent measles, pertussis, asthma, or any chronic cough in the family. Health workers who asked 1-2 points got a score of 1 (poor), 3-4 points got a score of 2 (fair), and 5+ points got a score of 3 (well done).

For physical examination according to WHO guidelines there were 9 points to be covered: count respiration rate, observe for chest indrawing, measure temperature, observe for stridor, observe for wheeze, observe for grunting, observe for consciousness, observe for severe malnutrition and observe for skin rash. A health worker who checked 1-2 points got a score of 1 (poor), 3-5 points got a score of 2 (fair), and 5+ points got a score of 3 (well done). The outcomes of the assessments were classified as:

- poor: below mean -1 standard deviation (SD) the performance was considered poor;

- well done: above mean +1 SD the performance was considered well done;

- fair: range between poor and well done.

\section{Diarrhoeal disease}

For reception and history taking according to WHO guidelines for diarrhoea cases, there were 8 points to be asked: appropriate reception, duration of diarrhoea, presence of blood/mucus in the stool, whether the child was urinating, presence of fever, cough or other important problems, food taken during the illness, drugs or other remedies taken and immunization history.

For physical examination according to WHO guide lines there were 6 points to be examined: pinch skin, observe for general condition (alert, restless or irritable, floppy, lethargic or unconscious), look for sunken eyes, check for sunken fontanel (if infant), observe for dry mouth and tongue and observe for nutritional status.

\section{Data analysis}

The data were recorded in a checklist. After each consultation, an independent assessment of the child was carried out by an experienced team member in another room strictly following WHO guidelines for ARI and diarrhoea to reach the diagnosis. Data were analysed using SPSS, version 11.

The chi-squared test for categorical variables was used and $P$-value $\leq 0.05$ was considered statistically significant. Corrected chi-squared was calculated whenever one of the cells had $<5$ responses/cases. 


\section{Results}

A total of 330 cases were selected, but 18 were excluded because of incomplete information, giving a sample of 312 children; 219 had ARI and 93 had diarrhoea. The care performance scores ranged from 21 to 39 (mean 30.04, SD 3.50).

A highly significant difference was found between medical doctors and medical assistants in their performance, since $91.2 \%$ of medical doctors had fair performance compared to $71.4 \%$ of medical assistants. Only $2.5 \%$ of medical doctors had poor performance compared to $25.0 \%$ of the medical assistants, the rest $(6.3 \%)$ of the medical doctors scored "well done" performance compared to $3.6 \%$ of medical assistants with well done performance $\left(\chi^{2}\right.$ $=30.3 ; P<0.0001)$. The performance was comparable for those who had attended a training course in ARI/AD and those who had not (Table 1).

Most of the health workers $(70.8 \%)$ reached a well founded diagnosis. No clear differences were found between different categories of health workers or according to years of experience or even according to attendance of ARI/CDD course.

Most of the medical doctors (55.3\%) scored fair for clinical history taking with $35.6 \%$ graded as poor clinical history taking, $8.8 \%$ graded well done clinical history taking and only $0.4 \%$ did not take the clinical history. In contrast, most of the medical assistants (71.4\%) scored poor for clinical history taking, with the rest scoring fair.

Medical doctors scored better than medical assistants with respect to performing physical examination (Table 2).

Regarding prescription of antibiotics, there was a statistically significant difference between medical doctors and medical assistants: doctors were more likely to make a correct choice $(48.6 \%)$ than medical assistants $(28.6 \%)\left(\chi^{2}=4.1, P=0.04\right)$.

Medical doctors and assistants were comparable $\left(\chi^{2}=0.78, P=0.38\right)$ in symptomatic drug prescription: medical doctors prescribed correct drugs for $63.0 \%$ $(179 / 284)$ of patients and medical assistants for $71.4 \%(20 / 28)$ of sick children.

Prescription of $\geq 3$ drugs was a common practice among both doctors and assistants (Table 3).

Health education of care-givers was not adequately practised by either category of health worker, as shown in Table 4.

\section{Discussion}

Quality assessment of healthcare provision aims to identify opportunities to improve most dimensions of quality, such as technical competence, effectiveness, efficiency, safety and coverage. It describes the current level of performance with the objective of improving it, training and motivating staff to undertake quality improvements, and

\begin{tabular}{|c|c|c|c|c|c|c|c|}
\hline \multirow[t]{3}{*}{ Training } & \multicolumn{7}{|c|}{ Performance } \\
\hline & \multicolumn{2}{|c|}{ Poor } & \multicolumn{2}{|c|}{ Fair } & \multicolumn{2}{|c|}{ Well done } & \multirow[t]{2}{*}{ Total } \\
\hline & No. & $\%$ & No. & $\%$ & No. & $\%$ & \\
\hline Attended & 4 & 3.0 & 121 & 91.7 & 7 & 5.3 & 132 \\
\hline Did not attend & 10 & 5.6 & 158 & 87.8 & 12 & 6.7 & 180 \\
\hline
\end{tabular}

$\chi^{2}=1.4, d f=2, \mathrm{P}=0.49$. 


\begin{tabular}{|c|c|c|c|c|c|c|c|c|c|}
\hline \multirow[t]{3}{*}{ Health worker } & \multicolumn{9}{|c|}{ Performance } \\
\hline & \multicolumn{2}{|c|}{ Well done } & \multicolumn{2}{|c|}{ Fair } & \multicolumn{2}{|c|}{ Poor } & \multicolumn{2}{|c|}{ Not done } & \multirow[t]{2}{*}{ Total } \\
\hline & No. & $\%$ & No. & $\%$ & No. & $\%$ & No. & $\%$ & \\
\hline Medical doctor & 16 & 5.6 & 150 & 52.8 & 117 & 41.2 & 1 & 0.4 & 284 \\
\hline Medical assistant & 0 & 0.0 & 8 & 28.6 & 18 & 64.3 & 2 & 7.1 & 28 \\
\hline Total & 16 & 5.1 & 158 & 50.6 & 135 & 43.3 & 3 & 1.0 & 312 \\
\hline
\end{tabular}

$\chi^{2}=19.9, d f=3, \mathrm{P}<0.0001$.

designing solutions to bridge the quality gap [8].

Our study revealed that the care provided in the health centres we studied was generally fair, with a small percentage of good care. Our findings are comparable to those reported about inadequate quality of care in rural West Bengal in India [5]. Our findings were not satisfactory since patients have the right to get good care. Health provision in our case seems to be focusing on coverage rather than quality. The concept of quality has recently been introduced to medical care provision in Yemen, and the performance of the medical care providers who have been trained is unfortunately not monitored, evaluated or audited.

In general, the performance differed according to category of health worker, with a highly significant difference between the well done performance of medical doctors and that of the medical assistants $(6.3 \%$ and $3.6 \%$ respectively). A fact that might explain this finding is the type and time taken in training received by the 2 groups. Another possible factor is that most of those who received on-the-job training on ARI and $\mathrm{AD}$ were doctors. This is in contrast to what has been found in another study in Malawi, where medical doctors scored lower than other health personnel [9].

The performance of health workers was to some extent better, although not statistically significantly, among those who had received training courses in ARI and $A D$ than that of colleagues who had not received training, a situation similar to that found in Saudi Arabia [3].

Most of the health workers reached a well founded diagnosis, with no clear differences between categories of health workers or attendance at an ARI/AD course. The proportion of workers who reached a correct diagnosis was unsatisfactory, since the diagnosis is straightforward and no sophisticated tools are needed. As a result, a misdiagnosing of an ARI or diarrhoeal case could lead to child death. The reason

Table 3 Number of drugs prescribed according to category of health worker

\begin{tabular}{|c|c|c|c|c|c|c|c|c|c|c|c|}
\hline \multirow[t]{3}{*}{ Health worker } & \multicolumn{11}{|c|}{ Number of drugs prescribed } \\
\hline & \multicolumn{2}{|c|}{1} & \multicolumn{2}{|c|}{2} & \multicolumn{2}{|c|}{3} & \multicolumn{2}{|c|}{4} & \multicolumn{2}{|c|}{5} & \multirow{2}{*}{$\begin{array}{c}\text { Total } \\
\text { No. }\end{array}$} \\
\hline & No. & $\%$ & No. & $\%$ & No. & $\%$ & No. & $\%$ & No. & $\%$ & \\
\hline Medical doctor & 12 & 4.2 & 76 & 26.8 & 114 & 40.1 & 71 & 25.0 & 11 & 3.9 & 284 \\
\hline Medical assistant & 1 & 3.6 & 4 & 14.3 & 13 & 46.4 & 9 & 32.1 & 1 & 3.6 & 28 \\
\hline Total & 13 & & 80 & & 127 & & 80 & & 12 & & 312 \\
\hline
\end{tabular}

$\chi^{2}=2.3, d f=4, \mathrm{P}=0.675$.

المجلة الصحية لشرق المتوسط، منظمة الصحة العالمية، المجلد الخامس عشر، العدد 0، 9. ب 


\begin{tabular}{|c|c|c|c|c|c|}
\hline \multirow[t]{2}{*}{ Health worker } & \multicolumn{2}{|c|}{ No advice } & \multicolumn{2}{|c|}{ Advice } & \multirow[t]{2}{*}{ Total } \\
\hline & No. & $\%$ & No. & $\%$ & \\
\hline Medical doctor & 167 & 58.8 & 117 & 41.2 & 284 \\
\hline Medical assistant & 12 & 42.9 & 16 & 57.1 & 28 \\
\hline Total & 179 & 100.0 & 133 & 100.0 & 312 \\
\hline
\end{tabular}

for insufficient diagnosis may be lack of supervision activities to monitor and follow up the workers' performance. Some provision for the parents in the health education component of ARI/AD could be given after covering the health personnel engaged in ARI/AD management by on-job training.

Regarding antibiotic choice, medical doctors were more likely than medical assistants to make a correct decision. However, performance of both was unsatisfactory since the proper antibiotic was prescribed by medical doctors in only $48.6 \%$ of cases. Improper prescription of antibiotics is likely directed to over-prescription, which is similar to the findings reported in Saudi Arabia [3]. The implications of this pattern of improper antibiotic prescription may be either misuse, in the case of diarrhoea, or life threatening, in the case of ARI. The majority of health workers $(70.2 \%)$ prescribed 3-5 drugs. This pattern of practice contradicts the WHO policies in treating such cases [2].

Most of the health workers did not educate patients' care-givers about the prevention and control of the illness. Health education was lacking also in other areas such as Pakistan [4]. This high proportion implies that these infections will continue spreading in the patients' families.

In conclusion, while the care provided in the health centres we studied was generally fair, there is considerable room for improvement and the general performance of all health providers should be promoted through training on ARI and CDD, and should be periodically evaluated.

\section{References}

1. World Health Organization, Division of Diarrhoeal and Acute Respiratory Disease Control. Integrated management of the sick child. Bulletin of the World Health Organization, 1995, 73:735-40.

2. IMCl information package, rev. 1. Geneva, World Health Organization, 1999 (WHO/CHS/CAH/98.1 A-M).

3. Khoja TA, al-Mohammad KK, Aziz KM. Setting the scene for an ARI control programme: is it worthwhile in Saudi Arabia? Eastern Mediterranean health journal, 1999, 5(1):111-7.

4. Igbal I, Pervez S, Baig S. Management of child with acute respiratory infections
(ARI) by general practitioners in Multan-an observation study. Journal of the Pakistan Medical Association, 1997, 47(1):24-8.

5. Chakraborty S, Frick K. Factors influencing private health providers' technical quality of care for acute respiratory infections among under-five children in rural West Bengal, India. Social science \& medicine, 2002, 55(9):1579-87.

6. Hector $\mathrm{G}$ et al. Quality improvement of integrated child health care management after in-service training for physicians. Family practice, 2003, 20(1):74-6. 
7. Country profiles, Yemen (Health status indicators). Cairo, World Health Organization Regional Office for the Eastern Mediterranean (http://www.emro.who.int/ index.asp?Ctry=yem, accessed 23 July 2006).

8. Assessing quality of healthcare at the district level in Rwanda. Quality Assurance Project case study. Bethesda, Maryland, Quality Assurance Project (Published for USAID), 1999 (http://www.qaproject.org/
pubs/PDFs/rwandacase.pdf, accessed 15 March 2009).

9. Lin Y, Franco LM. Assessing malaria treatment and control at peer facilities in Malawi. Quality Assurance Project case study. Bethesda, Maryland, Quality Assurance Project (Published for USAID), 2000 (http://www.qaproject.org/pubs/ PDFs/BIMI.PDF, accessed 23 January 2009).

The Work of WHO in the Eastern Mediterranean Region

This report is the first within the context of the medium-term strategic plan 2008-2013. As such it reflects the shift in the Organization's approach to its collaborative work with Member States, with programmes reporting against their expected results in relation to 13 cross-cutting strategic objectives for regional health development. The aim of this approach is to provide a more strategic and responsive programme structure that better reflects the needs of Member States and enhances collaboration with WHO's partners and within the Organization itself. The Work of WHO in the Eastern Mediterranean Region: Annual Report of the Regional Director 1 January-31 December 2008 is available on line at: http://www.emro.who.int/rd/annualreports/2008/Index.htm. 